\title{
Assessment of vertical ozone profiles from INSAT-3D sounder over the Central Himalaya
}

\author{
Prajjwal Rawat $^{1,2}$, Manish Naja ${ }^{1, *}$, Pradeep K. Thapliyal ${ }^{3}$, Shuchita Srivastava ${ }^{4}$, \\ Piyush Bhardwaj $^{5}$, Rajesh Kumar ${ }^{5}$, Samaresh Bhatacharjee ${ }^{1}$, S. Venkatramani ${ }^{6}$, \\ S. N. Tiwari ${ }^{2}$ and Shyam Lal ${ }^{6}$
}

\author{
${ }^{1}$ Aryabhatta Research Institute of Observational Sciences, Manora Peak, Nainital 263002 , India \\ ${ }^{2}$ DDU Gorakhpur University, Gorakhpur 273 009, India \\ ${ }^{3}$ Space Applications Centre, Jodhpur Tekra, Ahmedabad 380 015, India \\ ${ }^{4}$ Indian Institute of Remote Sensing, 4 Kalidas Road, Dehradun 248 001, India \\ ${ }^{5}$ National Center for Atmospheric Research, 3450 Mitchell Lane, Boulder, CO 80301, USA \\ ${ }^{6}$ Physical Research Laboratory, Navrangpura, Ahmedabad 380 009, India
}

\begin{abstract}
Vertical distribution of ozone has been obtained for the first time using INSAT-3D for the period 20132017 over the central Himalaya and validated utilizing balloon-borne observations from a high-altitude site in Nainital $\left(29.4^{\circ} \mathrm{N}, 79.5^{\circ} \mathrm{E}, 1793 \mathrm{~m}\right.$ amsl $)$. The INSAT $3 \mathrm{D}$ retrieved ozone profiles captured ozone gradient and ozone peak altitude successfully, despite only one IR channel for ozone. This demonstrates the capability of the INSAT-3D Sounder in capturing the observed features, with a smaller bias in the stratosphere and somewhat larger bias in the troposphere. Total ozone column from INSAT-3D showed maximum difference of $8 \%$ with ozonesonde-derived total ozone column. Larger ozone bias in the lower troposphere could be attributed to lower reliability of regression coefficient and INSAT-3D channel constraints itself, whereas high variability near the tropopause is possibly due to low ozone, poor temperature retrieval near the tropopause and stratosphere-troposphere transport process in the Himalayan region.
\end{abstract}

Keywords: Ozone profiles, ozonesonde, satellite data, vertical distribution.

OZONE plays an important role in influencing the thermal structure of the atmosphere through absorption in the longwave and shortwave spectral regions. It affects the global environment differently depending on its location in the atmosphere. Stratospheric ozone prevents harmful solar ultraviolet radiation from reaching the Earth's surface, while tropospheric ozone has deleterious effects on biological life and crop yields ${ }^{1-3}$. Photolysis of ozone in the troposphere followed by chemical reaction of excited oxygen atoms with large amounts of available water vapour in the troposphere produces hydroxyl radical that is a well-known 'detergent' for the oxidation of several trace gases ${ }^{4}$. Tropospheric ozone also absorbs infrared radiation near the terrestrial radiation peak and is regard-

*For correspondence. (e-mail: manish@aries.res.in) ed as the third most powerful greenhouse gas; it plays a vital role in the Earth's radiation budget. Therefore, it is essential to have realistic information on ozone vertical distribution over different regions of the world for accurate long-term climatology data, and improving numerical weather and air-quality predictions.

The rapid industrialization and urbanization in developing countries, particularly in Asia, is adding significant amounts of anthropogenic emissions in the atmosphere ${ }^{5}$. Ozone burden is also changing due to increase in emissions of its major precursors like carbon monoxide, oxides of nitrogen and volatile organic compounds. Therefore, continuous ozone monitoring is essential under such rapidly changing scenario. However, in situ ozone observations are sparse in South Asia. Space-borne observations are also challenging in the troposphere, specially in the lower troposphere and over regions of complex topography. The Himalayan region, located at the interface between the tropics and extra tropics, is often characterized by a split in the tropopause rather than continuous transition. Hence, frequent tropopause folding events lead to tropospheric ozone enhancement in the Himalayas ${ }^{6,7}$.

In view of this, INSAT-3D observations are utilized to obtain ozone profiles over the central Himalayan region. INSAT-3D is the only satellite in geo-stationary orbit for soundings over India. It was launched by the Indian Space Research Organisation (ISRO) on 26 July 2013 and carries imager and sounder payloads covering visible to long-wave infrared parts of the spectrum. Different validation studies have been done for temperature and water vapour from INSAT-3D ${ }^{8-10}$. The validation of ozone has been limited to the total column ozone only ${ }^{11}$. The ozone vertical distribution product from INSAT-3D has only been shown on algorithm development basis using principal component analysis, but it has not been validated so $\operatorname{far}^{12}$. The retrieval and validation of vertical ozone distribution from INSAT-3D are equally important, as they have the potential to provide vertical profiles of ozone with high temporal resolution for the Indian subcontinent. 
Table 1. INSAT-3D sounder data with corresponding resolution and accuracy

\begin{tabular}{llll}
\hline Parameter & Resolution & Expected accuracy \\
\hline Temperature profile & $50 \mathrm{~km} \times 50 \mathrm{~km}(5 \times 5$ pixels $) 40$ vertical pressure levels & $1^{\circ}-2^{\circ} \mathrm{C}$ \\
Water vapour profile & $50 \mathrm{~km} \times 50 \mathrm{~km}(5 \times 5$ pixels $)$ & 21 vertical pressure levels up to $100 \mathrm{hPa}$ & $\sim 30 \%$ \\
Ozone profile & $50 \mathrm{~km} \times 50 \mathrm{~km}(5 \times 5$ pixels $) 40$ vertical pressure levels & NA \\
Total column ozone & $50 \mathrm{~km} \times 50 \mathrm{~km}(5 \times 5$ pixels $)$ & $5-10 \%$ Dobson unit \\
Surface skin temperature & $50 \mathrm{~km} \times 50 \mathrm{~km}(5 \times 5$ pixels $)$ & $0.5^{\circ}-1^{\circ} \mathrm{C}$ \\
\hline
\end{tabular}

This study presents the first validated vertical ozone profiles from INSAT-3D sounder for a complete seasonal cycle. This is important and critical, considering the highly varying surface pressure over this region. In this perspective, we have utilized balloon-borne ozone observations from a high-altitude site (ARIES, Nainital) in the central Himalaya. The quality of temperature and $\mathrm{RH}$ profiles over the central Himalaya are also assessed.

\section{Data and methodology}

\section{INSAT-3D}

INSAT-3D is the first dedicated advanced meteorological Indian geostationary satellite, following earlier INSAT series that were primarily multipurpose satellites for telecommunications, broadcasting, meteorology, and search/ rescue needs of India. INSAT-3D carries two advanced meteorological instruments - imager and sounder, apart from the data relay transponder and satellite-aided search and rescue (SAS\&R) payloads. The INSAT-3D imager is an improved version of VHRR (very high resolution radiometer) with six channels dedicated to earth observations in high spatial and temporal resolution. The sounder is the first atmospheric sounding instrument on-board the geostationary INSAT series designed and developed at ISRO. The INSAT-3D sounder has 18 IR channels distributed over longwave and shortwave bands $(3.8-15 \mu \mathrm{m})$, with a visible channel for providing improved cloud detection ability during daytime. The primary objective of the sounder is to provide the vertical profiles of temperature and humidity, along with total column ozone over the Indian subcontinent with hourly temporal resolution. INSAT-3D takes $\sim 55$ min to scan the Indian land mass from the GEO orbit, and hence has additional advantage in terms of probability of finding clear pixels for retrieval of ozone and other meteorological parameters from 24 acquisitions of INSAT-3D versus 1-2 acquisitions from polar orbiting satellites within a day. Spatial resolution of the sounder is $10 \times 10 \mathrm{~km}$; however, for retrieval of atmospheric profiles an average of surrounding $5 \times 5$ pixels is used to reduce the noise and effect of fractional cloud contamination. Table 1 provides details of geophysical products with their corresponding resolution. The 18 sounder channels of INSAT-3D are given in the Supplementary Table 1, which shows the response of various channels towards different atmospheric constituents.

\section{Balloon-borne observations}

The INSAT-3D sounder data were evaluated using balloon-borne observations from ARIES, Nainital $\left(29.4^{\circ} \mathrm{N}\right.$, $\left.79.5^{\circ} \mathrm{E}, 1793 \mathrm{~m} \mathrm{amsl}\right)$. The balloon carries an electrochemical concentration cell (ECC) (model EN-SCI 2ZV7) ozonesonde ${ }^{13}$ and inter-Met 1 (iMet-1) radiosonde. The EN-SCI $2 \mathrm{ZV7}$ has participated in JOSIE (Juelich Ozone Sonde Intercomparison Experiment) international ozonesonde comparison, and standardization of operating procedures for ECC ozonesondes shows a precision better than $\pm(3-5) \%$ and an accuracy of about $\pm(5-10) \%$ up to $30 \mathrm{~km}$ altitude ${ }^{14}$. The balloon is generally launched between 11:00 and 12:00 h Indian Standard Time (IST) after clearances from local air-traffic control authorities. Balloon launch frequency is generally every week to fortnightly. The balloon burst altitude is mostly about $33 \mathrm{~km}$ (Figure 1) and it takes about $1 \frac{1}{2} \mathrm{~h}$ to reach that altitude. Some details of sensors, including their accuracy and response time are provided in the Supplementary Table 2; further details are available in the literature $^{13,15}$. The average vertical profiles were generated with vertical resolution of $100 \mathrm{~m}$ and data were filtered out beyond the range of $\pm 3 \sigma$ of mean values. This study used data from a total of 122 flights launched between October 2013 and December 2017. The average factor of total ozone for ozonesonde with INSAT-3D physical (regression) and ozone monitoring instrument (OMI) total ozone observations showed values of $0.96 \pm 0.06$ $(0.99 \pm 0.07)$ and $1.02 \pm 0.05$ respectively, which are well within the range of World Meteorological Organization (WMO) criteria ${ }^{16}$.

\section{MERRA-2 reanalysis data}

We have used temperature, relative humidity (RH) and ozone data from Modern-Era Retrospective analysis for Research and Applications version-2 (MERRA-2) for comparison. MERRA-2 is a reanalysis product based on an upgraded version of the Goddard Earth Observing System Model, version 5 (GEOS-5) data assimilation system. The key components of the reanalysis are the GEOS atmospheric model and GSI analysis scheme. All data collections from MERRA-2 are provided on the same horizontal grid. There are 576 grid points in the longitudinal direction and 361 grid points in the latitudinal direction, corresponding to a resolution of $0.625^{\circ} \times 0.5^{\circ}$. 


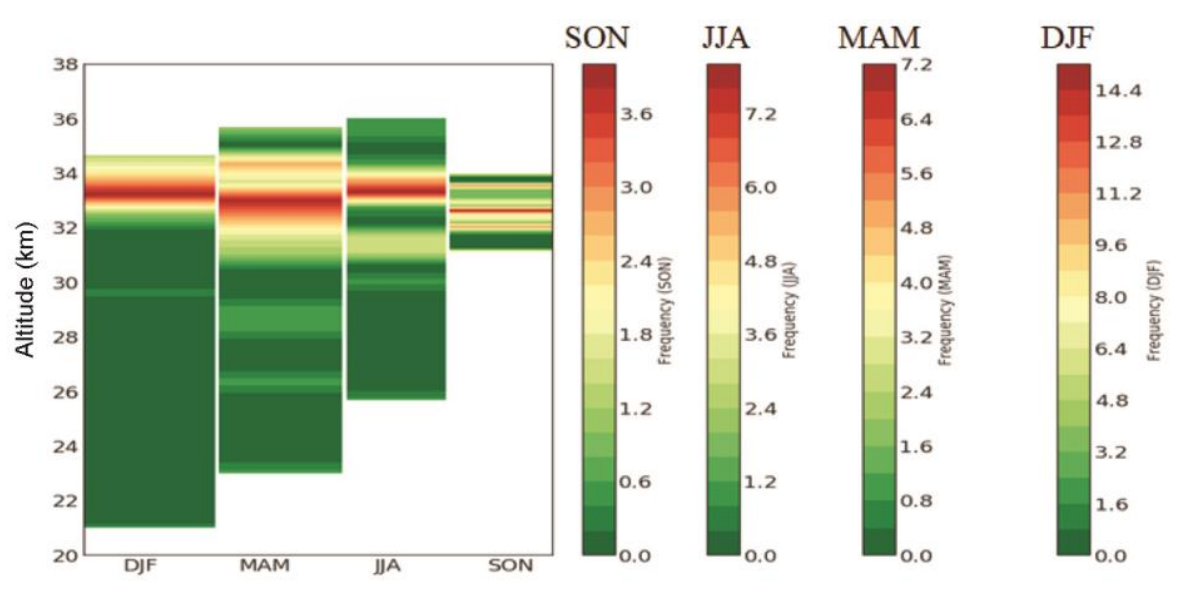

Figure 1. Balloon burst altitude frequency during four seasons. Different scales are used for different seasons to emphasize more on the burst altitude frequency.

Table 2. Details of limits of the ozone values considered for quality control in INSAT-3D analysis at different altitudes

\begin{tabular}{lccc}
\hline & & Ozonesonde minimum and maximum range $(\mathrm{ppb})$ \\
\cline { 2 - 3 } Altitude $\mathrm{hPa}(\mathrm{km})^{*}$ & $\mathrm{DJF}$ & MAM & JJA \\
\hline$>250(<10.5)$ & $21-172$ & $7-198$ & $21-148$ \\
$250-150(10.5-14.5)$ & $34-379$ & $7-398$ & $48-132$ \\
$150-100(14.5-16.5)$ & $57-559$ & $7-740$ & $54-120$ \\
$100-70(16.5-18.5)$ & $114-1476$ & $17-1457$ & $62-477$ \\
$70-50(18.5-20.5)$ & $225-2688$ & $229-3592$ & $8-139$ \\
$<50(>20.5)$ & $10-20,000$ (this range is considered during all seasons) & $7-991$ \\
\hline
\end{tabular}

*Values are ranged within the INSAT-3D standard pressure levels in hPa and their corresponding altitude in km is shown in brackets.

It uses the native vertical grid (at 72 model layers), or interpolated to 42 standard pressure levels from the surface to $0.01 \mathrm{hPa}$. MERRA-2 data files are provided in netCDF format. We have used 06:00 GMT data of MERRA-2 for appropriate comparison of data products.

\section{AIRS and OMI observations}

Atmospheric infrared sounder (AIRS) and OMI observations were also utilized to evaluate the goodness of INSAT retrieved products. AIRS on-board Aqua satellite, is a polar orbit satellite at $705 \mathrm{~km}$ altitude, with equatorial crossings at $\sim 13: 30 \mathrm{~h}$ (ascending node) and having a hyperspectral infrared grating spectrometer for earth observations. The 2378 independent channels on AIRS help in the retrieval of an entire profile in the presence of up to $90 \%$ cloud fraction, with an aid of cloud clearing using collocated MODIS and AMSU data. For this study, AIRS level-2 version-6 (AIRS2RET) data with horizontal resolution of roughly $50 \times 50 \mathrm{~km}$ were used (corresponding to $3 \times 3$ AIRS pixels). The atmospheric profiles are available at 28 vertical pressure levels for temperature and ozone, whereas only 15 vertical pressure levels for RH up to $100 \mathrm{hPa}$. OMI on-board Aura satellite, is a nadirviewing ultraviolet-visible $(270-500 \mathrm{~nm})$ hyperspectral imaging spectrometer with high spatial resolution $(13 \times 24 \mathrm{~km}$ at nadir $)$ that provides high-quality ozone column observations based on differential optical absorption spectroscopy (DOAS) technique. For this study, we have used level-3 Aura/OMI global OMDOAO3e data products that provide total column ozone globally.

\section{INSAT-3D data retrieval}

INSAT-3D retrieval algorithm is described briefly here and details can be found in INSAT-3D Algorithm Theoretical Basis Document (ATBD) (https://mosdac.gov.in/ data/doc/INSAT 3D_ATBD_MAY 2015.pdf). First, a cloud-detection routine was used to identify the clear-sky pixels. The identification of cloudy pixels was done based on thresholds in various visible and infrared window channels. After each pixel in the sounder, observations were classified as clear or cloudy; the clear-sky brightness temperature in 18 channels was computed by averaging the clear pixels from the surrounding $5 \times 5$ pixels (corresponding to $50 \mathrm{~km} \times 50 \mathrm{~km}$ at nadir) making field of regard (FOR) for the retrieval. If more than nine pixels (roughly one-third) in the FOR are cloudy, then the FOR is termed as cloudy and retrieval is not attempted. Averaging over larger FOR $(50 \mathrm{~km} \times 50 \mathrm{~km})$ was done to 
reduce the noise in the observations as well as to reduce the effect of small fractional cloud cover that might go undetected during cloud detection routine.

The retrieval of atmospheric profiles was accomplished for clear-sky FOR using a two-step algorithm. First, a nonlinear statistical regression of sounder brightness temperature against atmospheric state was performed using a training dataset of diverse profiles. Next, we made use of the physical retrieval algorithm, where first guess was provided either from the regression retrieval or forecast from Global Forecast System (GFS), whichever was better. The physical retrieval algorithm makes use of a fast radiative transfer model and using a first guess profile attempts to finds a solution that best fits the satellite observation by utilizing a nonlinear iterative method ${ }^{17}$. Here at each iteration, a convergence test was carried out on brightness temperature residual. The iteration was stopped once this residual became smaller than the threshold value that depends on instrument noise. The physical retrieval was considered as failed, if the iterative process failed to converge, and brightness temperature residual increased with iterations and did not approach instrument noise. The physical retrieval algorithm is computationally expensive due to several iterations in the estimation; however, computational time decreases using accurate first guess (regression retrievals or GFS forecast). The final data products of INSAT-3D had 40 vertical pressure levels $(\mathrm{hPa})$ at: 1000, 950, 920, 850, 750, 700, 670, 620, 570, 500, 475, 430, 400, 350, 300, 250, $200,150,135,115,100,85,70,60,50,30,25,20,15$, $10,7,5,4,3,2,1.5,1,0.5,0.2,0.1$. Considering the altitude $(1793 \mathrm{~m}$ amsl) of the observation site, data from $850 \mathrm{hPa}$ onwards were used in the present analysis.

Furthermore, INSAT-3D water vapour mixing ratios were converted to RH to compare with radiosonde observations (see Supplementary Material). The RH data from INSAT-3D were also compared with AIRS-retrieved relative humidity.

\section{Collocation criteria, INSAT-3D data quality control and statistical analysis}

We have used 6 and 7 GMT (between 11:30 and 13:30 h IST) observations of INSAT-3D to match the timing of ozonesonde observations. Further, for spatial collocation, we have used INSAT-3D observations within the region $29.2^{\circ}-29.6^{\circ} \mathrm{N}$ and $79.3^{\circ}-79.7^{\circ} \mathrm{E}$. Additionally, there are no quality flags in INSAT-3D data at present and we have encountered very large or unrealistic values in INSAT-3D regression ozone data (mostly in the troposphere).

Therefore, such data were discarded based on minimum and maximum ozone values observed by ozonesonde at different altitudes and seasons, i.e. winter (DJF), spring (MAM), summer-monsoon (JJA) and autumn
(SON) as mentioned in Table 2. In addition, we have also applied a $2 \sigma$ filters at 85 and $100 \mathrm{hPa}$ levels to remove outliers. This filtering has led to the removal of $4.94 \%$ of ozone data from the INSAT-3D sounder observations. A simple statistical analysis was also carried out to examine the relative difference between retrieval parameters and actual observations to further assess the capability of INSAT-3D retrievals. In these calculations, we represent balloon-borne observations as sonde. For temperature, the absolute difference was calculated (INSAT-sonde); however for $\mathrm{RH}$ and ozone relative bias in percentage was calculated (((INSAT - Sonde)/Sonde) * 100) which are similar to statistics used in the previous validation study of AIRS ozone retrieval ${ }^{18}$.

\section{Results and discussion}

\section{Temperature}

Both physical and regression-retrieved temperature profiles from INSAT-3D were compared with radiosonde and reanalysis data during four seasons (Figure 2). The INSAT-3D physical retrieval temperature profiles were in better agreement with radiosonde and MERRA-2 reanalysis

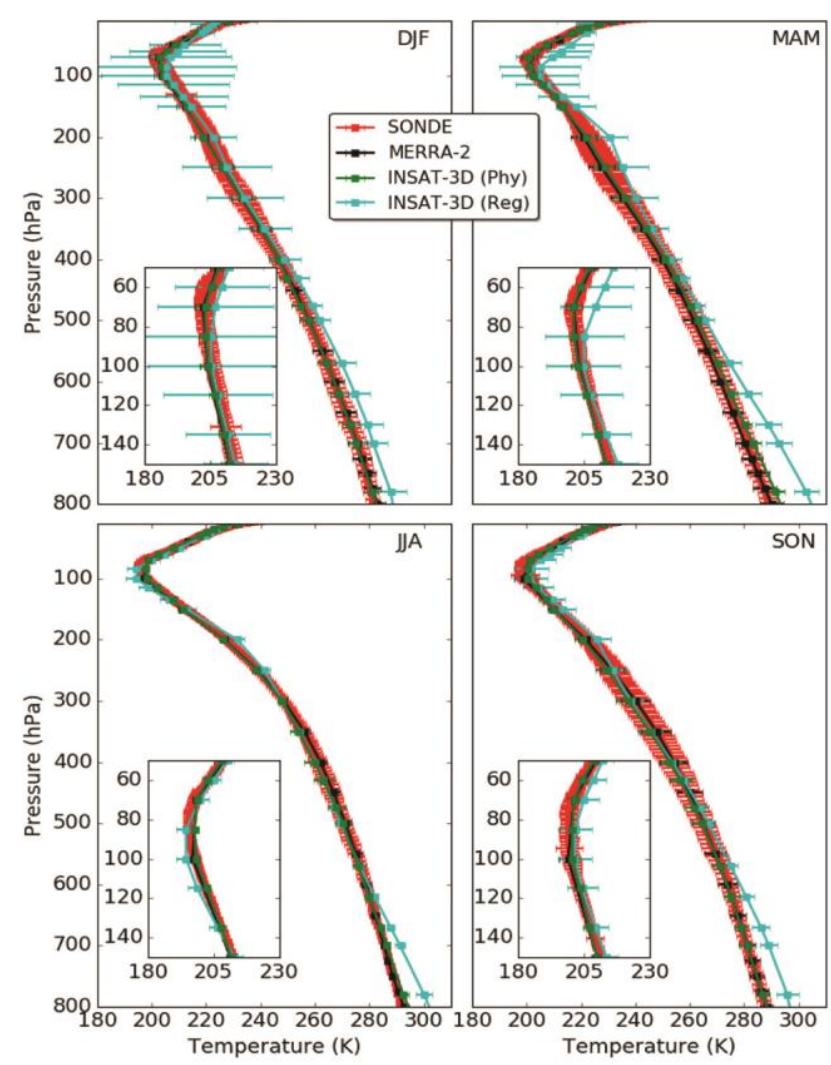

Figure 2. Average seasonal temperature profiles using INSAT-3D (physical and regression retrievals) and radiosonde observations at Nainital and MERRA-2 reanalysis data. Zoomed profile near tropopause $(150-50 \mathrm{hPa})$ is also shown for each season. 
data with biases smaller than $2 \mathrm{~K}$, compared to the regression temperature retrieval used as first guess along with the GFS forecast for final physical retrieval. The INSAT-3D regression retrieval showed large biases of up to about $5 \mathrm{~K}$ near the surface and up to about $-8 \mathrm{~K}$ at greater heights. Figure 2 also shows comparison around tropopause $(150-50 \mathrm{hPa})$, where the temperature gradient changed from unstable atmosphere to highly stable atmosphere (inset of each panel). Larger variability was observed near the tropopause, particularly during winter and spring. Regression retrievals showed good agreement with radiosonde observations in parts of the upper troposphere $(100-150 \mathrm{hPa})$, except in summer. The temperature bias of less than $2 \mathrm{~K}$ in the physical retrievals (Figure $3 a$ ) was well within the range of biases of $0.5-4 \mathrm{~K}$ in other validation studies ${ }^{8,19}$. On an annual basis, INSAT-3D temperature is positive bias or slightly negative bias up to $500 \mathrm{hPa}$, and negative bias at greater altitudes.

Cold point tropopause (CPT) temperature was also estimated for INSAT-3D and compared with that from radiosonde (Figure 4). CPT is the upper limit of tropical
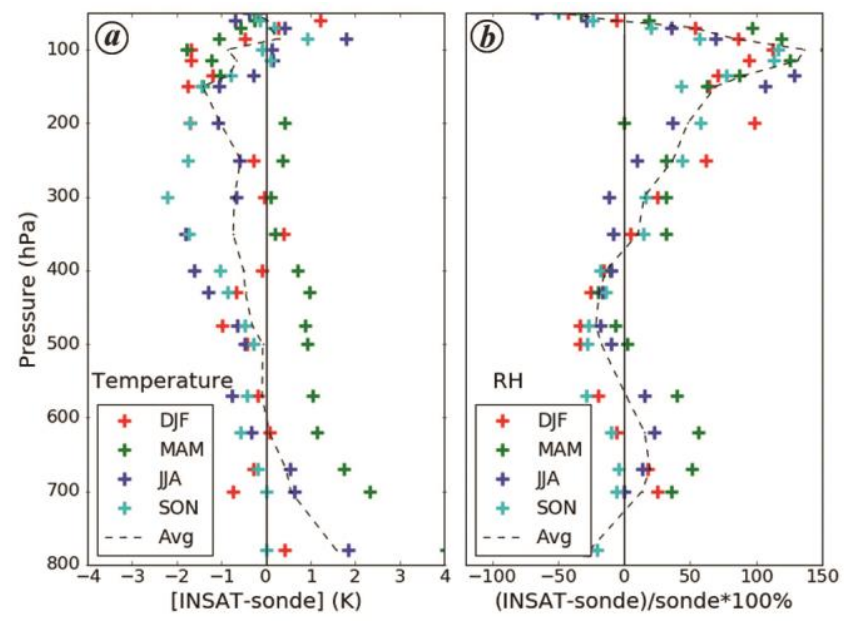

Figure 3. Mean relative difference of INSAT-3D physical retrieved (a) temperature and $(\boldsymbol{b})$ relative humidity with respect to ozonesonde observations.

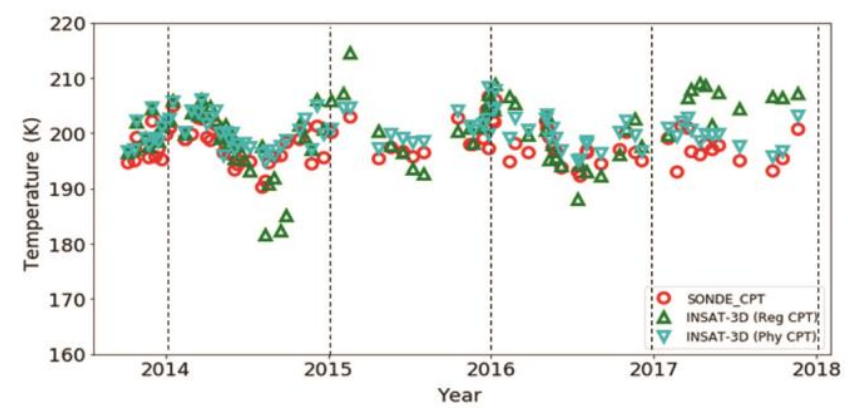

Figure 4. Cold point tropopause (CPT) time series using INSAT-3D (physical and regression methods) and radiosonde observations over the central Himalaya. tropopause layer, a region between the troposphere and stratosphere. CPT temperature showed a clear seasonal variation with higher temperature and greater variability during winter and early spring. CPT temperature from physical retrieval showed lesser variability $(1.5 \%)$ than the regression method $(7.3 \%)$. CPT from radiosonde showed variability of $2.7 \%$. The CPT height was used to calculate the tropospheric ozone column.

\section{Relative humidity}

Figure 5 compares vertical distribution of $\mathrm{RH}$ from INSAT-3D, radiosonde, AIRS and MERRA-2 reanalysis. INSAT-3D physical retrieval and MERRA-2 data showed better agreement with radiosonde data, mainly during winter and autumn. Major differences were observed in spring below $550 \mathrm{hPa}$, although AIRS data showed better agreement with radiosonde in this season. Generally, RH values were underestimated ( 21\%) by INSAT-3D, AIRS and MERRA-2 below $750 \mathrm{hPa}$ when compared with radiosonde data. At greater altitudes, up to about $570 \mathrm{hPa}$, INSAT-3D observations were overestimated. After a slight changeover, a positive bias was again seen above $400 \mathrm{hPa}$ in INSAT-3D (Figure $3 \mathrm{~b}$ ); it was as high as $136 \%$ at $115 \mathrm{hPa}$. The $\mathrm{RH}$ values from radiosonde at above $200 \mathrm{hPa}$ levels were not accurate; nevertheless, consistent biases of satellite and reanalysis products at this altitude could have some contribution from retrieval error and variable surface topography within the FOR.

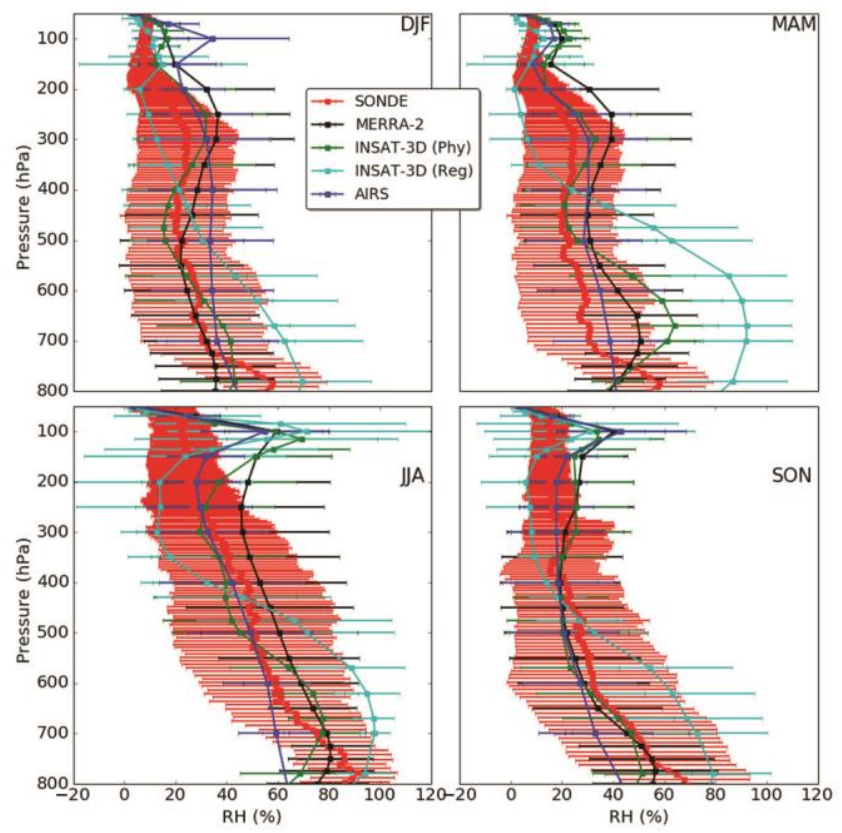

Figure 5. Seasonal relative humidity profiles using balloon-borne observations, MERRA-2 reanalysis data, AIRS retrieval and INSAT$3 \mathrm{D}$ satellite retrieval data, both physical and regression retrieval. 
Table 3. Ozone values for different seasons at various altitudes as observed by ozonesonde and INSAT-3D

\begin{tabular}{|c|c|c|c|c|c|c|c|c|}
\hline \multirow[b]{2}{*}{ Altitude (hPa) } & \multicolumn{4}{|c|}{ INSAT-3D (ppb) } & \multicolumn{4}{|c|}{ Ozonesonde (ppb) } \\
\hline & DJF & MAM & JJA & SON & DJF & MAM & JJA & SON \\
\hline 780 & $63 \pm 27$ & $76 \pm 23$ & $77 \pm 22$ & $60 \pm 23$ & $51 \pm 9$ & $67 \pm 20$ & $52 \pm 20$ & $50 \pm 9$ \\
\hline 700 & $61 \pm 25$ & $74 \pm 18$ & $71 \pm 17$ & $61 \pm 19$ & $54 \pm 6$ & $67 \pm 20$ & $57 \pm 21$ & $52 \pm 12$ \\
\hline 620 & $58 \pm 20$ & $73 \pm 15$ & $68 \pm 14$ & $61 \pm 15$ & $55 \pm 8$ & $65 \pm 19$ & $64 \pm 20$ & $53 \pm 12$ \\
\hline 500 & $54 \pm 15$ & $68 \pm 13$ & $67 \pm 10$ & $58 \pm 9$ & $54 \pm 7$ & $68 \pm 18$ & $69 \pm 25$ & $62 \pm 15$ \\
\hline 300 & $51 \pm 13$ & $64 \pm 11$ & $66 \pm 12$ & $51 \pm 11$ & $65 \pm 17$ & $74 \pm 32$ & $79 \pm 14$ & $71 \pm 16$ \\
\hline 200 & $79 \pm 57$ & $89 \pm 24$ & $77 \pm 21$ & $61 \pm 15$ & $103 \pm 56$ & $120 \pm 60$ & $83 \pm 15$ & $82 \pm 22$ \\
\hline 115 & $82 \pm 41$ & $64 \pm 52$ & $51 \pm 12$ & $58 \pm 53$ & $163 \pm 81$ & $163 \pm 137$ & $122 \pm 28$ & $121 \pm 60$ \\
\hline 100 & $165 \pm 141$ & $57 \pm 16$ & $47 \pm 12$ & $53 \pm 24$ & $218 \pm 91$ & $219 \pm 133$ & $143 \pm 27$ & $137 \pm 70$ \\
\hline 70 & $494 \pm 320$ & $302 \pm 98$ & $259 \pm 56$ & $250 \pm 89$ & $611 \pm 291$ & $577 \pm 313$ & $419 \pm 153$ & $456 \pm 167$ \\
\hline 50 & $1276 \pm 426$ & $1425 \pm 312$ & $1362 \pm 252$ & $1175 \pm 33$ & $1746 \pm 572$ & $1654 \pm 645$ & $1785 \pm 312$ & $1526 \pm 381$ \\
\hline
\end{tabular}

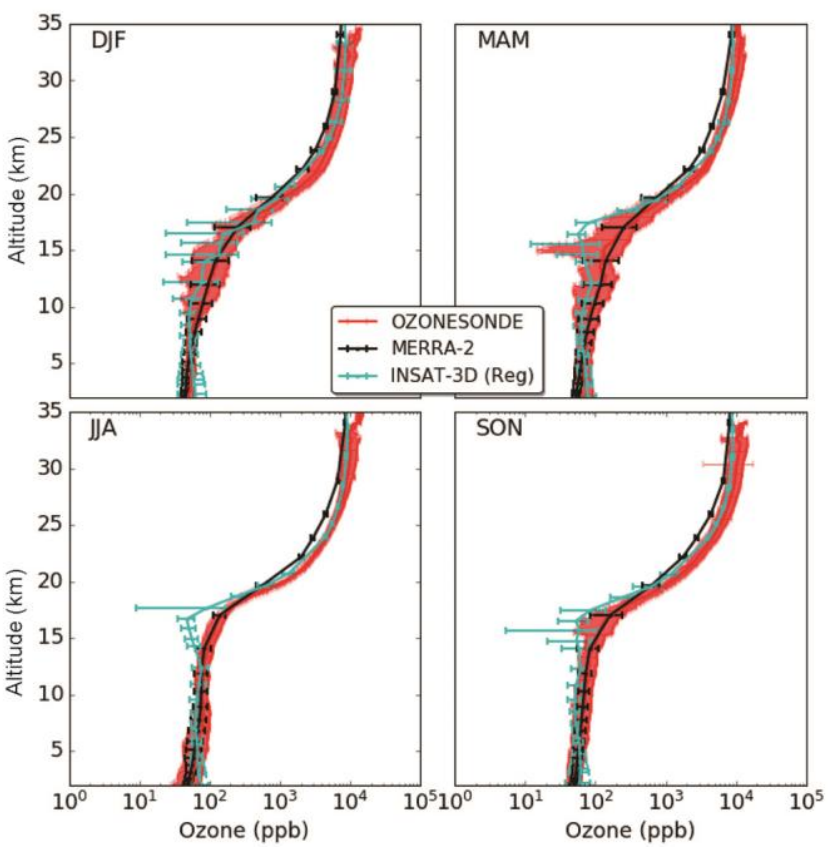

Figure 6. Seasonal ozone profiles using balloon-borne observations, INSAT-3D and MERRA-2 reanalysis data.

\section{Ozone profiles}

Figure 6 shows vertical distribution of ozone from INSAT-3D, ozonesonde and MERRA-2 during four seasons. Figure 7 shows average distribution of ozone in the troposphere during each month. Ozone vertical distributions form INSAT-3D observations agreed fairly well with ozonesonde, particularly in the stratosphere. INSAT3D ozone values were lower than the ozonesonde values in some parts of the upper and middle troposphere. While MERRA-2 values were lower than the ozonesonde observations in the stratosphere, with better agreement in the troposphere. Further, better agreement between INSAT 3D and ozonesonde was seen in the lower troposphere (below $5 \mathrm{~km}$ ), including the boundary layer.

INSAT-3D ozone retrieval showed higher variability near the tropopause region as indicated by higher stan- dard deviation (Table 3). This is mainly due to very sharp ozone gradients and dynamic nature of the tropopause. The INSAT-3D temperature regression product also showed large variability near the tropopause. This reflects the dependence of ozone retrievals on temperature profile in INSAT-3D retrieval algorithm. Frequent tropopause folding during winter and early spring may introduce additional ozone variability near the tropopause. Limitation of one ozone channel in INSAT-3D sounder could also be another contributing factor. It is to be noted that INSAT-3D underestimates ozone value near the tropopause in all seasons, except winter when it matches reasonably well with the ozonesonde values. This underestimation is also reflected in monthly profiles (Figure 7) from March onwards, and it is seen down to the middle troposphere. During the summer-monsoon season, a relatively lower variability with greater underestimation near tropopause was observed, which could be due to relatively lower ozone near the tropopause during summer as ozone poor air could have been pumped to greater heights through monsoon convections ${ }^{20}$. Additionally, lower number of retrievals because of prevalent cloudy conditions of summer contribute to lesser variability in ozone. The MERRA-2 reanalysis ozone data showed a consistent profile in the troposphere and an underestimation in the stratosphere during all seasons.

\section{Total ozone and tropospheric ozone column}

Total ozone was calculated by integrating the amount of ozone in the layers between two pressure labels up to balloon-burst altitude, and then adding either residual ozone or satellite-derived balloon-burst climatology $(\mathrm{BBC})^{21}$. The method to calculate total ozone using ozonesonde data is described as follows

$$
\left.\Omega_{\text {total }}=\Omega_{\mathrm{o} 3}+\Omega_{\mathrm{R}} \text { (or climatology value }\right),
$$

where $\Omega_{03}$ is integrated ozone from the surface to the balloon-burst altitude, and $\Omega_{\mathrm{R}}$ is residual ozone above the balloon burst altitude which can be calculated using 

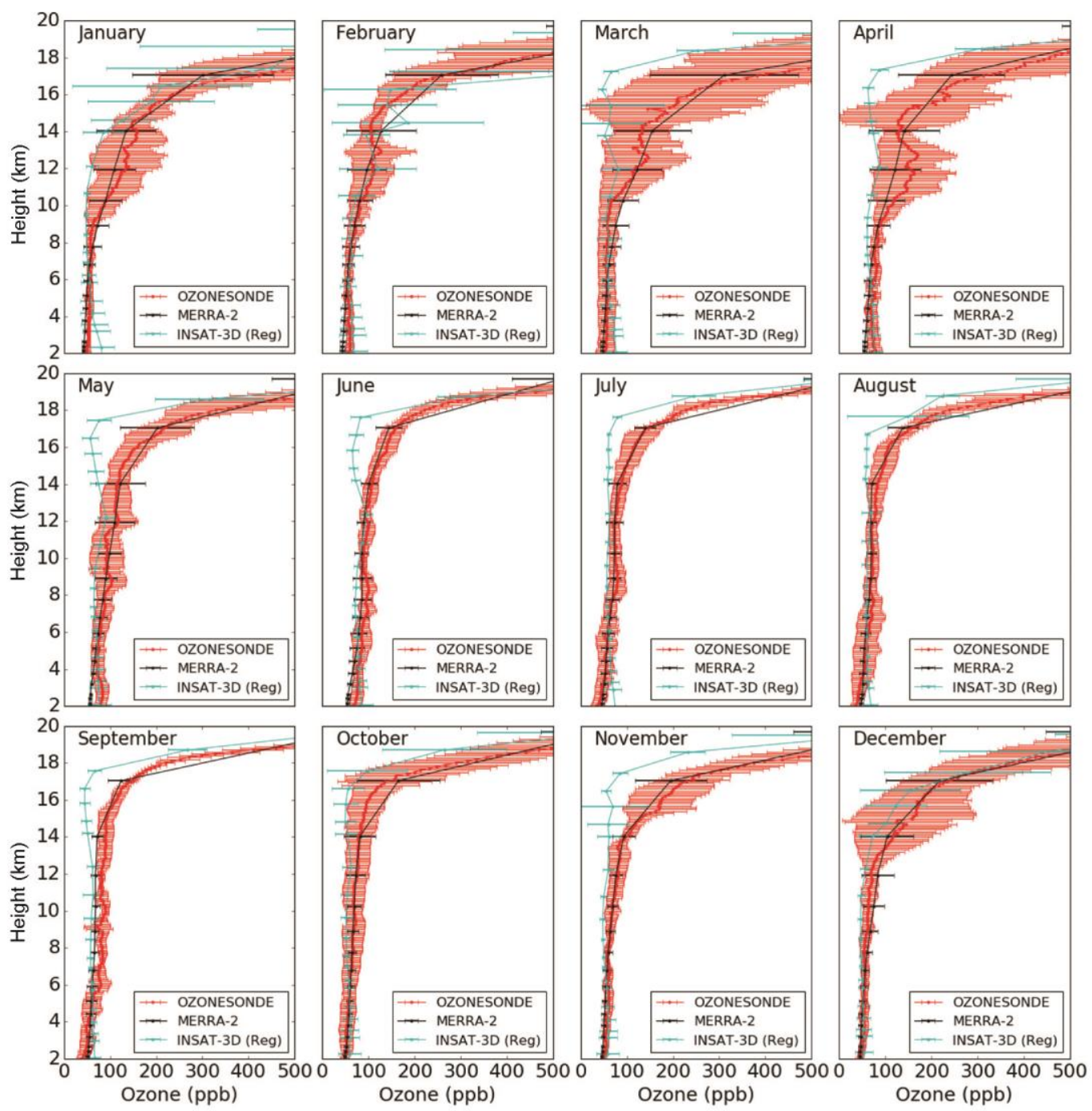

Figure 7. Monthly tropospheric ozone profiles using balloon-borne observations, MERRA-2 reanalysis data and INSAT-3D regression retrieval data.

different methods. Here we have used satellite-based BBC method (see Supplementary Material for a detailed description). We have also estimated total ozone using constant mixing ratio (CMR) method; but it showed consistently higher values (20-35 DU), throughout the year than other observations. This overestimation could be due to choice of the constant top of the atmosphere and use of CMR down to the burst altitude. Therefore, total ozone column estimated using CMR method was not used here.

Figure 8 shows monthly variations in total ozone from ozonesonde, INSAT-3D (both regression and physical retrieval) and OMI. The seasonal variations were reasonably similar; however, they were some differences in their values. The difference of INSAT-3D total ozone was up to about $8 \%$ (about $22 \mathrm{DU}$ ) with ozonesonde, while difference with OMI was up to $11 \%$ (about 33 DU) (Table 4). The regression method showed larger variability than the physical method more-or-less during each month.
INSAT-3D total ozone showed a difference from -22 to 8 DU with ozonesonde, while the difference ranged from -33 to -2 DU with OMI (Table 4). The difference between ozonesonde and OMI ranged from -24 to $1 \mathrm{DU}$. Total ozone from INSAT-3D showed reasonable agreement with ozonesonde in late autumn and winter, while INSAT-3D values were lower during spring and summermonsoon.

Tropospheric ozone column can be calculated either using the tropospheric residual method or the integration method with integration from surface to tropopause. In the present study we used CPT as the upper limit of the troposphere for both ozonesonde and INSAT-3D regression retrieval, and $850 \mathrm{hPa}$ as the surface level for INSAT-3D. Since INSAT-3D has coarser vertical resolution, it produces an uncertainty of $1-2 \mathrm{~km}$ in the CPT calculation equivalent of 1-5 DU uncertainty in the tropospheric ozone column. Further to minimize the errors earlier, we have considered the tropospheric ozone 


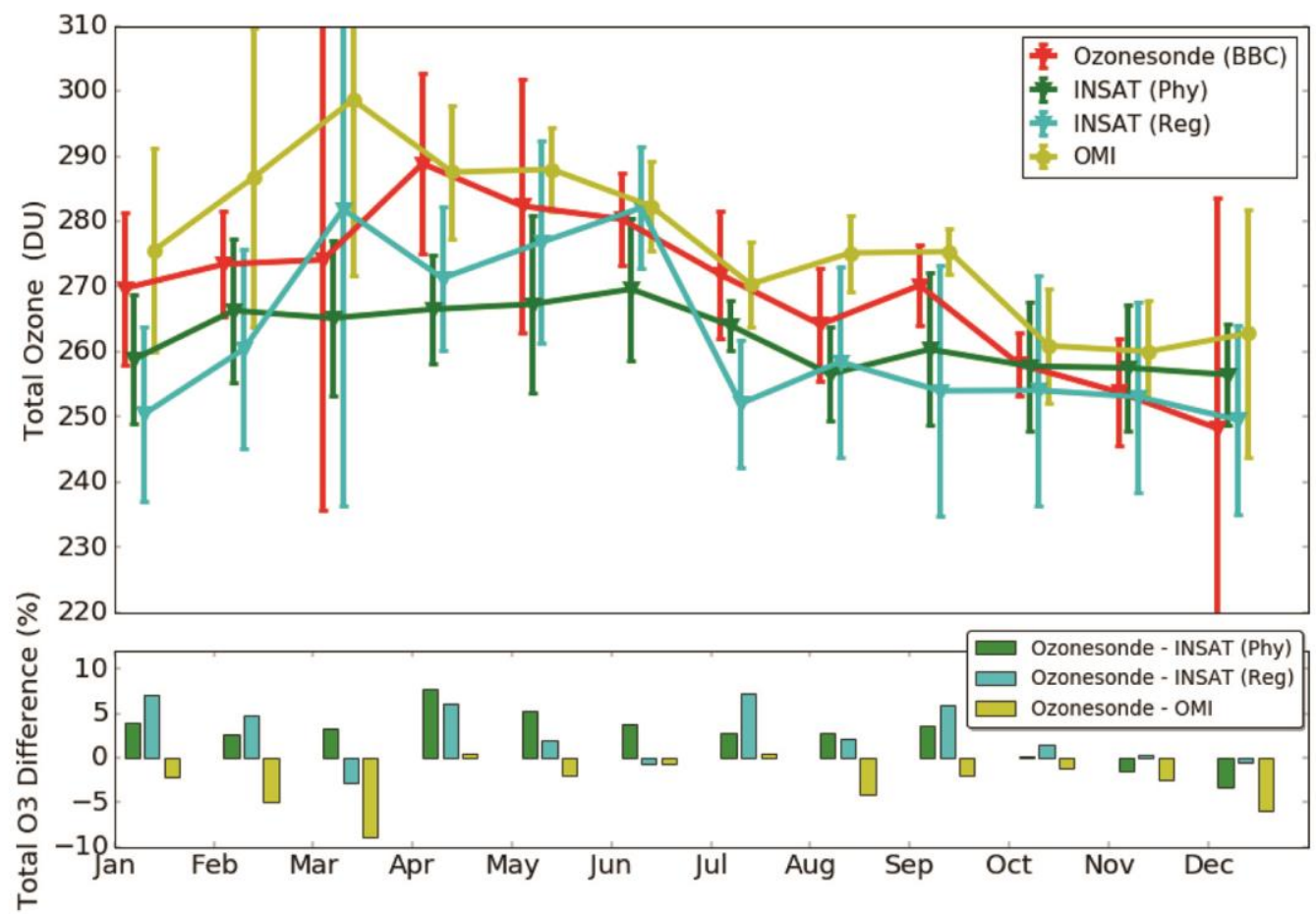

Figure 8. (Top panel) Monthly variations in total ozone from ozonesonde observations, INSAT-3D retrieval (regression and physical retrieval) and ozone monitoring instrument (OMI). (Bottom panel) Percentage difference of satellite products with respect to ozonesonde.

Table 4. Difference (DU) in total ozone among ozonesonde, ozone monitoring instrument (OMI) and INSAT-3D physical retrievals during 12 months

\begin{tabular}{lccc}
\hline Month & $\begin{array}{c}\text { INSAT }- \\
\text { Ozonesonde }\end{array}$ & $\begin{array}{c}\text { INSAT }- \\
\text { OMI }\end{array}$ & $\begin{array}{c}\text { Ozonesonde - } \\
\text { OMI }\end{array}$ \\
\hline January & -10.9 & -16.7 & -5.9 \\
February & -7.1 & -20.4 & -13.3 \\
March & -9.0 & -33.5 & -24.5 \\
April & -22.4 & -21.0 & 1.3 \\
May & -15.1 & -20.7 & -5.6 \\
June & -10.7 & -12.7 & -2.0 \\
July & -7.8 & -6.3 & 1.4 \\
August & -7.6 & -18.6 & -11.0 \\
September & -9.8 & -15.0 & -5.2 \\
October & -0.3 & -3.1 & -2.8 \\
November & 3.7 & -2.5 & -6.2 \\
December & 8.3 & -6.3 & -14.6 \\
\hline
\end{tabular}

column values well within the range $10-100$ DU as an additional quality control. Figure 9 shows tropospheric ozone column from ozonesonde and INSAT-3D regression retrieval during four seasons along with synergetic observation of OMI and Micro Limb Sounder (MLS)derived tropospheric ozone column. Tropospheric ozone column from INSAT-3D was lower by about 8 DU in spring, by about $3 \mathrm{DU}$ in autumn and comparable in winter and summer. Tropospheric ozone column from OMI/MLS showed similar seasonal variations; however the values were somewhat lower. This underestimation of tropospheric ozone by OMI/MLS could be due to use of lapse rate tropopause instead of CPT.
All observations showed higher values of tropospheric ozone column during spring which was dominated by transport of ozone-rich air from the stratosphere and photochemical ozone production, in addition to contribution from North Indian biomass burning ${ }^{22}$. Tropospheric ozone column decreased during monsoon, when southwesterly winds dominate and bring pristine marine air masses $^{23,24}$. The stratospheric intrusion was also minimal during this period ${ }^{25}$. The annual average tropospheric ozone column from INSAT-3D (40 \pm 3 DU) was slightly lower than the ozonesonde ( $44 \pm 5 \mathrm{DU})$.

\section{Relative bias analysis in ozone}

Relative bias analysis of INSAT-3D ozone retrieval product with ozonesonde was performed at each vertical level and the mean relative bias is discussed here. On an annual basis, INSAT-3D observations were positively biased (up to $26 \%$ ) in the lower troposphere and negatively biased (up to 56\%) near the tropopause (Figure 10). On the seasonal basis, maximum positive bias was seen during summer monsoon (48\%) in the lowermost layer. Largest negative bias was seen near the tropopause with maximum negative bias during spring (about -77\%) and minimum during winter, with a tendency of positive bias too. Bias was almost negligible in the stratosphere. Principal component analysis also showed similar high biases in INSAT-3D ozone retrieval in the lower stratosphere ${ }^{8}$. This negative bias in INSAT-3D decreased gradually at higher altitudes and became almost negligible near $10 \mathrm{hPa}$. 


\section{Discussion and summary}

INSAT-3D was launched to support communication and meteorological research. It carries the imager and sounder payloads covering visible to longwave infrared. The prime objective of the sounder is to provide vertical profiles of temperature and water vapour over the Indian subcontinent, apart from total column ozone. So far no study has evaluated ozone vertical distribution using INSAT-3D observations. Additionally, none of the validation studies on temperature and $\mathrm{RH}$ considered

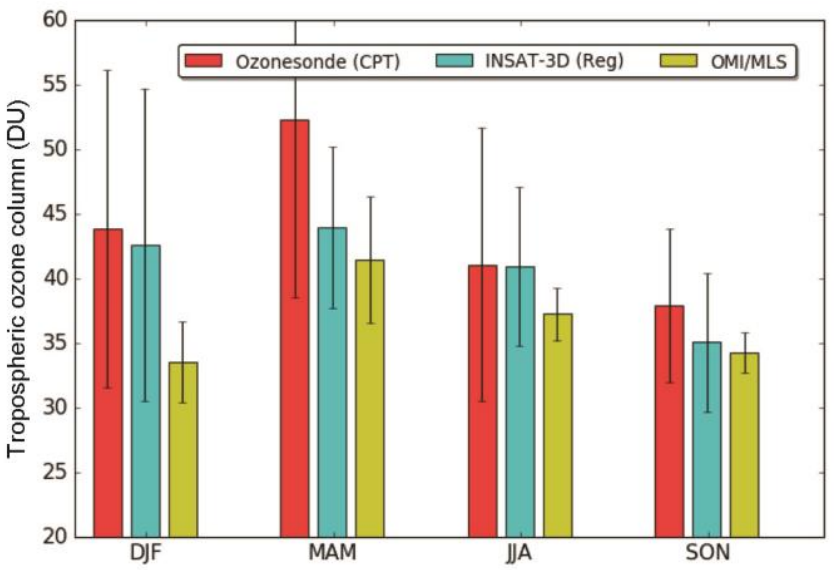

Figure 9. Tropospheric ozone column derived from INSAT-3D ozone regression retrieval, ozonesonde and OMI/MLS data.

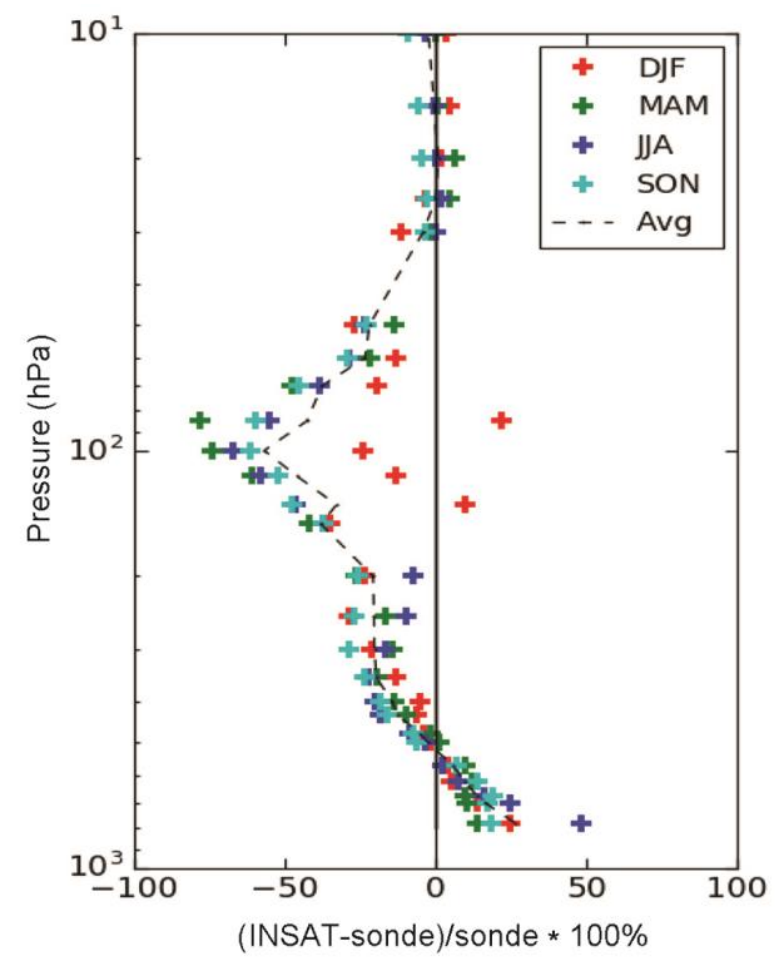

Figure 10. Mean relative bias in INSAT-3D ozone regression retrieval with ozonesonde observations during the four seasons. the complex topography of the central Himalayan region, where surface pressure is about $800 \mathrm{hPa}$ with large variations within an FOR of $50 \times 50 \mathrm{~km}$. Here, INSAT-3D observations have been used to obtain the vertical ozone distribution for all 12 months over the central Himalayan region. They were validated with the help of ozonesonde observations from Nainital during 20132017.

The vertical profiles of temperature from INSAT-3D (physical retrieval) showed a good agreement with radiosonde and MERRA-2 reanalysis product with biases less than $2 \mathrm{~K}$ over the central Himalayan region. Similarly, the physical product of RH profiles showed a significant improvement when compared with regression retrieval. The improvements in physical retrieval were mainly due to the sufficient use of INSAT-3D sounder radiances apart from the best first guess from regression retrieval and GFS forecast.

Vertical ozone profiles obtained from INSAT-3D sounder were in reasonable agreement, particularly in the stratosphere, with ozonesonde observations over the central Himalaya. It has been observed that ozone vertical profiles were somewhat underestimated by INSAT-3D in the troposphere. Total ozone column and tropospheric ozone column from INSAT-3D also agreed reasonably well with ozonesonde and OMI. Total ozone column showed a maximum difference up to $22 \mathrm{DU}$ and the tropospheric ozone column showed a maximum difference of 8 DU when compared with ozonesonde. INSAT3D observations were positively biased (up to 26\%) in the lower troposphere, negatively biased (up to 56\%) near the tropopause and had nearly negligible bias in the stratosphere. The present study shows that the INSAT-3D sounder is able to produce the ozone gradient and ozone peak altitude correctly, and hence demonstrates the capability of INSAT-3D ozone retrieval algorithm.

During recent years, global interest in earth-observing geostationary satellites has increased rapidly due to their high temporal resolution which could be used for studying diurnal variations of trace gases, aerosols and meteorology. Recently, South Korea has launched a geostationary environment monitoring spectrometer (GEMS) satellite covering the Asian region, including most parts of India. The present study shows that there is a great potential to obtain more accurate data by improving the input regression product of INSAT-3D. Though INSAT3D has only one channel for ozone retrieval, the ozone profile and ozone peak altitude can be effectively retrieved. In view of this, it is desirable that more ozoneabsorbing channels be added in future missions for better retrieval of vertical ozone distribution. This will add more value to the already existing platform/payloads. Further efforts are needed to improve the regression retrieval for ozone profile, particularly over the regions of variable topography and high mountains. 
1. Mauzerall, D. L. and Wang, X. P., Protecting agricultural crops from the effects of tropospheric ozone exposure: reconciling science and standard setting in the United States, Europe, and Asia. Annu. Rev. Energy Environ., 2001, 26, 237-268.

2. Desqueyroux, H., Pujet, J. C., Prosper, M., Squinazi, F. and Momas, I., Short-term effects of low-level air pollution on respiratory health of adults suffering from moderate to severe asthma. Environ. Res., 2002, 89, 29-37.

3. Lal, S., Venkataramani, S., Naja, M., Kuniyal, J. C., Mandal, T. K and Bhuyan, P. K., Loss of crop yields in India due to surface ozone: an estimation based on a network of observations, Environ. Sci. Pollut. Res., 2017, 24(26), 20972-20981.

4. Brasseur, G. P., Orlando, J. J. and Tyndall, G. S., Atmospheric Chemistry and Global Change, Oxford University Press, New York, USA, 1999, pp. 209-234.

5. Kumar, R., Barth, M. C., Pfister, G. G., Delle Monache, L. and Lamarque, J. F., How will air quality change in South Asia by 2050? J. Geophys. Res.: Atmos., 2018, 123(3), 1840-1864.

6. Ojha, N. et al., On the processes influencing the vertical distribution of ozone over the central Himalayas: analysis of year-long ozonesonde observations. Atmos. Environ., 2014, 88, 201-211; doi:10.1016/j.atmosenv.2014.01.031.

7. Naja, M. et al., High-frequency vertical profiling of meteorological parameters using AMF1 facility during RAWEX-GVAX at ARIES, Nainital. Curr. Sci., 2016, 111(1), 132-140.

8. Ratnam, V. M., Kumar, A. H. and Jayaraman, A., Validation of INSAT-3D sounder data with in situ measurements and other similar satellite observations over India. Atmos. Meas. Tech. 2016, 9, 5735-5745; doi:10.5194/amt-9-5735-2016

9. Singh, T., Mittal, R. and Shukla, M. V., Validation of INSAT-3D temperature and moisture sounding retrievals using matched radiosonde measurements. Int. J. Remote Sensing, 2017, 38(11), 3333-3355; doi:10.1080/01431161.2017.1294776

10. Rao, V. K. et al., Validating INSAT-3D atmospheric temperature retrievals over India using radiosonde measurements and other satellite observations. Meteorol. Atmos. Phys., 2019, https://doi. org/10.1007/s00703-019-00710-8.

11. Jindal, P., Thapliyal, P. K., Shukla, M. V., Mishra, A. K. and Mitra, D., Total column ozone retrieval using INSAT-3D sounder in the tropics: a simulation study. J. Earth Syst. Sci., 2014, 123(6), 1265-1271.

12. Jindal, P., Shukla, M. V., Sharmac, S. K. and Thapliyal, P. K., Retrieval of ozone profiles from geostationary infrared sounder observations using principal component analysis. Q. J. R. Meteorol. Soc., 2016, 142, 3015-3025; doi:10.1002/qj.2884.

13. Komhyr, W. D., Barnes, R. A., Brothers, G. B., Lathrop, J. A. and Opperman, D. P., Electrochemical concentration cell ozonesonde performance evaluation during STOIC 1989. J. Geophys. Res., 1995, 100(D5), 9231-9244; http://dx.doi.org/10.1029/94JD02175.

14. Smit, H. G. J. et al., Assessment of the performance of ECCozonesondes under quasi-flight conditions in the environmental simulation chamber: insights from the Juelich Ozone Sonde Intercomparison Experiment (JOSIE). J. Geophys. Res., 2007, 112, D19306; 10.1029/2006JD007308.

15. Johnson, B. J., Oltmans, S. J. and Vömel, H., Electrochemical concentration cell (ECC) ozonesonde pump efficiency measure- ments and tests on the sensitivity to ozone of buffered and unbuffered ECC sensor cathode solutions. J. Geophys. Res., 2002, 107(D19), 4393; doi:10.1029/2001JD000557.

16. WMO, Sources of errors in detection of ozone trends. Global Ozone Research and Monitoring Project Report 12, World Meteorological Organization, Geneva, 1982, p. 12.

17. Li, J., Wolf, W. W., Menzel, W. P., Zhang, W., Huang, H. L. and Achtor, T. H., Global sounding of the atmosphere from ATOVS measurements: the algorithm and validation. J. Appl. Meteorol., 2000, 39, 1248-1268.

18. Bian, J., Gettelman, A., Chen, H. and Pan, L. L., Validation of satellite ozone profile retrievals using Beijing ozonesonde data. $J$. Geophys. Res., 2007, 112, D06305; doi:10.1029/2006JD007502.

19. Mitra, A. K., Bhan, S. C., Sharma, A. K., Kaushik, N., Parihar, S., Mahandru, R. and Kundu, P. K., INSAT-3D vertical profile retrievals at IMDPS, New Delhi: a preliminary evaluation. Mausam, 2015, 66(4), 687-694.

20. Park, M., Randel, W. J., Gettelman, A., Massie, S. T. and Jiang, J. H., Transport above the Asian summer monsoon anticyclone inferred from Aura Microwave Limb Sounder tracers. J. Geophys. Res., 2007, 112, D16309; doi:10.1029/2006JD008294.

21. McPeters, R. D., Labow, G. J. and Johnson, B. J., A satellitederived ozone climatology for balloonsonde estimation of total column ozone. J. Geophys. Res., 1997, 102, 8875-8885.

22. Bhardwaj, P., Naja, M., Kumar, R. and Chandola, H. C., Seasonal, interannual, and long-term variabilities in biomass burning activity over South Asia. Environ. Sci. Pollut. Res., 2015, doi:10.1007/s11356-015-5629-6.

23. Srivastava, S., Naja, M. and Thouret, V., Influences of regional pollution and long range transport over Hyderabad using ozone data from MOZAIC. Atmos. Environ., 2015, 117, 135-146.

24. Lal, S., Venkataramani, S., Srivastava, S., Gupta, S., Mallik, C. and Naja, M., Transport effects on the vertical distribution of tropospheric ozone over the tropical marine regions surrounding India. J. Geophys. Res.: Atmos., 2013, 118(3), 1513-1524.

25. Lal, S., Venkataramani, S., Chandra, N., Cooper, O. R., Brioude, J. and Naja, M., Transport effects on the vertical distribution of tropospheric ozone over western India. J. Geophys. Res.: Atmos., 2014, 119(16), 10012-10026.

ACKNOWLEDGEMENTS. This work is supported by the ISROATCTM project. The INSAT-3D products are provided by ISRO via MOSDAC. Help from Deepak and Nitin during balloon launches and coordination by the air traffic control is acknowledged. We thank the Directors of ARIES, SAC and IIRS for support. This study based upon work supported by the National Center for Atmospheric Research, USA a major facility sponsored by the National Science Foundation under Cooperative Agreement No. 1852977. S.L. thanks CSIR, New Delhi for the Emeritus Scientist position. We also thank the editor and two reviewers for their constructive comments.

Received 7 May 2020; revised accepted 17 July 2020

doi: $10.18520 / \mathrm{cs} / \mathrm{v} 119 / \mathrm{i} 7 / 1113-1122$ 